\title{
AGRICULTURA FAMILIAR, POLÍTICAS PÚBLICAS E MERCADOS INSTITUCIONAIS: UMA ANÁLISE EXPLORATÓRIA DO PROGRAMA NACIONAL DE ALIMENTAÇÃO ESCOLAR - PNAE NO RIO GRANDE DO NORTE
}

\author{
T. F. DIAS ${ }^{1}$, E. F.OLIVEIRA ${ }^{2}$ \\ Universidade Federal do Rio Grande do Norte \\ tfdpe@yahoo.com.br ${ }^{1}$
}

Artigo submetido em 18/01/2018 e aceito em 09/08/2019

DOI: $10.15628 /$ holos.2019.6838

\section{RESUMO}

A agricultura familiar aponta-se como importante instrumento catalisador de mudanças no espaço rural, de modo que, várias políticas públicas têm sido direcionadas ao seu fortalecimento. Diversas ações conduzem para constituição e consolidação de mercados loco-regionais voltados aos produtores familiares, visando em especial, suprir os desafios e entraves ao desenvolvimento deste setor, tal como a comercialização de seus produtos. Nesta linha destaca-se o Programa de Aquisição de Alimentos - PAA (2003) e a vinculação de um percentual mínimo de 30\% para compra da merenda escolar diretamente da agricultura familiar local, previsto nas alterações do Programa Nacional de Alimentação Escolar (2009), pois, além de se constituírem como elementos centrais para viabilizar a produção agrícola familiar contribuem para o desenvolvimento socioterritorial e a segurança alimentar e nutricional. Desta maneira, o estudo analisou de forma exploratória a execução do PNAE no Rio Grande do Norte a partir dos resultados alcançados pelas escolas públicas estaduais entre os anos de 2011 e 2013, auferindo seu cumprimento legal e prospectando contribuições para a agricultura familiar a partir do desempenho e operacionalização desta política pública. À luz das referências bibliográficas, levantamento documental e combinação de procedimentos metodológicos de abordagem qualitativa e quantitativa, verificou-se que embora o Estado tenha alcançado a média total de $26,2 \%$ do porcentual de recursos a serem aplicados na compra de produtos da agricultura familiar, sob a ótica da regionalização interna, o desempenho das Diretorias Regionais de Alimentação Escolar (DRAEs) é bastante diverso e conflitivo.

PALAVRAS-CHAVE: Agricultura Familiar, Mercados Institucionais, Alimentação Escolar.

\section{FAMILY AGRICULTURE, PUBLIC POLICIES AND INSTITUTIONAL MARKETS: AN EXPLORATORY ANALYSIS OF THE NATIONAL SCHOOL FEEDING PROGRAM - PNAE IN RIO GRANDE DO NORTE}

\section{ABSTRACT}

Family farming is an important catalyst for changes in rural areas, so that several public policies have been directed towards its strengthening. Numerous actions lead to the constitution and consolidation of locoregional markets aimed at family producers, aiming in particular to meet the challenges and obstacles to the development of this sector, as well as the commercialization of their products. This line includes the Food Acquisition Program - PAA (2003) and the linkage of a minimum percentage of $30 \%$ to purchase school meals directly from the local family agriculture, foreseen in the changes in the National School Feeding Program - PNAE (2009) as well as being central elements for the viability of family agricultural production contribute to socio-territorial development and food and nutritional security. In this way, the study analyzed in an
\end{abstract}

exploratory way the PNAE implementation in Rio Grande do Norte from the results achieved by the state public schools between the years of 2011 and 2013, obtaining its legal compliance and prospecting contributions to family agriculture from the performance and operationalization of this public policy.

In the light of bibliographical references, documentary survey and combination of methodological procedures of qualitative and quantitative approach, it was verified that although the State has reached the total average of $26,2 \%$ of the percentage of resources to be applied in the purchase of products of the familiar agriculture, from the point of view of internal regionalization, the performance of the Regional School Feeding Offices (DRAEs) is quite diverse and conflicting.

KEYWORDS: Family farming, Institutional Markets, School Feeding. 


\section{INTRODUÇÃO}

No limiar dos anos 1990 a reestruturação produtiva protagonizada em meio ao avanço da atividade agroexportadora e o cenário de competitividade regida pela "flexibilização" dos mercados coagiu grande parcela dos pequenos produtores rurais brasileiros a buscar mecanismos alternativos de produção e comercialização de seus produtos, assim como postular uma reação mais forte à perspectiva hegemônica da economia de mercado. De maneira independente e paralela ao modelo de produção dominante, a emergência de novas práticas, dinâmicas e formas organizativas (fruto de distintas experiências de contestação ao paradigma vigente) e estratégias coletivas de geração de trabalho e renda no campo, buscou estabelecer modelos de desenvolvimento alternativo com ênfase na produção associativa, colaborativa e cooperativa e a construção de outras destas formas, assim como a autogestão e integração de empreendimentos econômico-solidários.

O fortalecimento da agricultura familiar e a consolidação dos mercados loco-regionais estabelecidos através da implementação de políticas públicas emergentes nos anos de 2000, inauguram novas formas de relacionamento entre o Estado, o mercado e a sociedade. Estes elementos foram componentes estratégicos no apoio a produção, comercialização e consumo de produtos agrícolas. A partir da criação de mercados institucionais, através do Programa de Aquisição de Alimentos (PAA), em 2003, e mais recentemente com Programa Nacional de Alimentação Escolar (PNAE) - no âmbito da Lei Federal № 11.947/2009 que assegura a destinação de no mínimo 30\% dos recursos repassados pelo Fundo Nacional de Desenvolvimento da Educação (FNDE) para a aquisição da alimentação escolar oriundas da agricultura familiar - construiu-se no país um arcabouço político-institucional e jurídico-legal que objetiva atacar o principal dilema e desafio e entrave ao desenvolvimento da agricultura familiar: a comercialização de seus produtos.

Seja como "categoria política e funcional para canalizar os recursos do Estado" na busca pelo crescimento econômico (Sabourin et al, 2014) ou como vetor de desenvolvimento socioterritorial, a agricultura familiar tem contribuído fortemente para a construção de uma nova expressão do ambiente rural. Segundo o IBGE (2006), os empreendimentos agrícolas de origem familiar correspondem a $84,4 \%$ dos estabelecimentos rurais, respondendo por aproximadamente $40 \%$ da produção agrícola nacional, dos quais pelo menos $70 \%$ destinam-se a abastecer o consumo interno de alimentos, isto é, alimentos para o consumo na mesa do brasileiro. Além disso, a agricultura familiar gera no Brasil mais de $80 \%$ de ocupação no setor rural e corresponde por 7 em cada 10 empregos no campo (BRASIL, 2015).

De acordo com Grisa e Schneider (2014), tal cenário nos revela com nitidez o papel significativo que a agricultura familiar contemporânea exerce na dinâmica econômica e social do país, na promoção da seguridade alimentar e nutricional e na soberania alimentar, como também na busca por uma maior eficiência produtiva no uso da terra. Para tanto, o presente artigo se dispõe analisar de forma exploratória a execução do PNAE no Rio Grande do Norte a partir dos resultados alcançados pelas escolas públicas estaduais entre os anos de 2011 e 2013, auferindo cumprimento legal e prospectando contribuições para a agricultura familiar a partir do desempenho e operacionalização desta política pública. Com os resultados há a possibilidade 
verificar se os empreendimentos econômico-solidários da agricultura familiar e instituições de caráter local estão se articulando e aproveitando (ou não) a oportunidade de vincular sua produção agrícola a necessidade de aquisição de alimentos dos programas governamentais.

\section{POLÍTICAS PÚBLICAS E AGRICULTURA FAMILIAR: trajetórias frente à segurança alimentar e nutricional e o desenvolvimento socioterritorial rural}

A integração das políticas públicas focalizadas na agricultura familiar pode constituir um modelo efetivo de desenvolvimento socioterritorial no meio rural (Turpin, 2009), baseando-se na redução das desigualdades sociais de uma localidade e/ou região, como também na mitigação das disparidades espaciais (urbano $\mathrm{x}$ rural) e no fortalecimento da economia local. Contudo, a trajetória destas iniciativas não tem sido linear: entre avanços e retrocessos, extinções e emergências, continuidades e descontinuidades, as políticas públicas de desenvolvimento rural e segurança alimentar e nutricional no Brasil têm exercido nas últimas décadas um papel de destaque no combate à miséria e o flagelo social da fome e redução da mortalidade causada pela desnutrição infantil, na busca pelo crescimento econômico e pelo estabelecimento de um "novo cenário de inovação e estímulo ao desenvolvimento territorial endógeno" (CUNHA et al, 2014, p.17) diante da conjuntura social no campo.

Aquino et al. (2011, p.3) sustenta que "até o início da década de 1990, não havia nenhum tipo de política pública específica, com abrangência nacional, voltada para o segmento social formado pelos produtores rurais familiares no Brasil". Em que pese o ensaio governamental brasileiro com a implantação em 1994 do Programa de Valorização da Pequena Produção Rural (PROVAP), cujos "impactos e resultados junto aos agricultores familiares não se mostraram convincentes (Brasil, 2014, p.4)". De modo que, foi o movimento liderado pela CONTAG (Confederação Nacional dos Trabalhadores na Agricultura), denominado "Primeiro Grito da terra Brasil" que pressionou em busca da concepção do Programa Nacional de Fortalecimento da Agricultura Familiar (PRONAF). Responsável por estabelecer um sistema de crédito (subsidiado, capital de giro, investimentos), o programa foi desenhado no sentido de "promover o desenvolvimento sustentável do segmento rural constituído pelos agricultores familiares, de modo a propiciar-lhes o aumento da capacidade produtiva, a geração de empregos e a melhoria de renda" (Brasil, 1996, p.1).

A criação do Ministério do Desenvolvimento Agrário (MDA) em 1999, fruto também de reivindicações de atenção institucional pleiteada pelos movimentos sociais campesinos, selou o compromisso e assumiu a responsabilidade de resgatar e impulsionar o potencial da agricultura familiar, em âmbito da União.

A chegada de um governo progressista em 2003, com a eleição de Luis Inácio Lula da Silva (2003 - 2010), introduziu uma nova arquitetura político-institucional corroborando com importantes aportes neste processo: amplia-se o leque de políticas estruturantes direcionadas ao atendimento das demandas dos produtores rurais por meio de estratégias de combate à fome e a miséria e promoção da agricultura familiar, organizadas em torno da Estratégia Fome Zero.

Estruturado em quatro eixos (acesso a alimentos; fortalecimento dos agricultores familiares; geração de renda; prestação de contas e mobilização social), o arquétipo da Estratégia Fome Zero baseou-se na gestão articulada de programas governamentais a partir da 
"racionalização das políticas públicas de superação da insegurança alimentar e nutricional no país" (PINTO, 2014a, p. 21). Estes eixos foram associados e integrados as políticas de assistência social, inclusão produtiva, transferência de renda, constante oferta de serviços públicos de saúde e educação. Como linha importante desta iniciativa, o Programa de Aquisição de Alimentos (PAA) instituído pela Lei Federal $N^{\circ} 10.696$, de 2 de Julho de 2003, e regulamentado pelo Decreto no 7.775, de 4 de julho de 2012, integra o Sistema Nacional de Segurança Alimentar e Nutricional (SISAN) e tem como finalidades principais incentivar a agricultura familiar, promovendo a sua inclusão econômica e social, com fomento à produção com sustentabilidade, ao processamento de alimentos e industrialização e à geração de renda.

O PAA apresenta uma trajetória de bastante sucesso rumo à inclusão produtiva de milhares de agricultores familiares brasileiros, "com cerca de 400 mil beneficiários fornecedores distribuídos em 2.698 municípios do Brasil em três modalidades: Compra com Doação Simultânea - CDS, Apoio à Formação de Estoques e Compra Direta da Agricultura Familiar - CDAF" (CONAB, 2015).

Ainda assim, o PAA apresenta desafios transcendentais no plano logístico-operacional, sobretudo no que se trata da descentralização, transporte de alimentos, divulgação de suas ações, seleção dos agricultores beneficiários, desburocratização dos processos, liberação de recursos e mecanismos de pagamento, assistência técnica e obtenção da DAP (Declaração de Aptidão ao Pronaf).

Sparovek et al. (2007) argumenta que o programa fez surgir novas relações entre produtores familiares de alimentos, intermediários ou "atravessadores", agentes públicos e autoridades locais e, instituições privadas e consumidores, de modo a alterar a viabilidade dos sistemas alimentares locais. Este sistema de relações e participação social na implementação e execução do PAA, parte da premissa que a interação entre os distintos atores e agentes sociais permita a geração de associativismo, cooperativismo e empreendedorismo na agricultura familiar, baseada na cooperação mútua e na multiplicação dessas tecnologias sociais.

O capital social resultante das múltiplas iniciativas e arranjos organizacionais tem assumido um papel significativo na operacionalização do PAA e na direção da melhoria no desempenho institucional em suas variadas escalas, conferindo-o cada vez mais "legitimidade social nos espaços político-institucionais" (Cunha et al., 2014, p.23).

Uma outra grande conquista refere-se a iniciativa de articular as compras públicas de alimentos para a merenda escolar com a agricultura familiar, no âmbito das mudanças na legislação brasileira no que se trata da operacionalização da Programa Nacional de Alimentação Escolar (PNAE). Isto ocorreu com a descentralização dos recursos financeiros do FNDE (Fundo Nacional de Desenvolvimento da Educação) através da Lei 8.913 de 12/7/94, no qual delegou competências as redes municipais e estaduais de ensino no atendimento a alimentar e nutricional dos alunos, e as recentes alterações realizadas pela sanção da Lei $N^{\circ} 11.947 / 2009$, que traz a extensão do programa para toda a rede pública de educação básica (municipal, estadual e federal), inclusive aos alunos do Programa Mais Educação e do EJA (Educação de Jovens e Adultos) e fixa a aplicação mínima de $30 \%$ dos repasses financeiros do FNDE para o investimento na aquisição de gêneros alimentícios da agricultura familiar local. A conexão entre agricultura familiar e a merenda escolar corroboram para que o programa tenha "o potencial de oferecer um mercado institucional expressivo para os produtores de alimentos (IPC-IG, 2013, p. 19)". 
Tal programa, que tem sua origem entre as décadas de 1930 e 1940 (somente em 1979 passa a denominar-se PNAE), é tido como "uma das maiores e mais antigas políticas públicas do Brasil (Saraiva et al.,2013, p. 928)". Tal longevidade deve-se ao fato da iniciativa ter incorporado ao seu escopo inicial (puramente nutricional) o viés econômico e social, de modo que o objetivo de oferecer uma alimentação saudável e equilibrada aos alunos de escolas públicas brasileiras (conforme o artigo 208 da Constituição Federal) e promover o direito humano a alimentação adequada, e ao mesmo tempo estivesse relacionada aos elementos de produção, acesso e consumo de alimentos, a redução da pobreza e insegurança alimentar no campo, a dinamização das economias locais e valorização do cultivo agrícola familiar.

Em 2014, o orçamento do Programa alocou quase $\mathrm{R} \$ 3,7$ bilhões para beneficiar 42,2 milhões de estudantes da educação básica e de jovens e adultos. Desta ótica, considerando apenas o cumprimento do mínimo legal de $30 \%$ estabelecido para a compra direta de gêneros alimentícios agrícolas através da dispensa do processo licitatório, a agricultura familiar teria assegurada uma demanda estruturada/institucional de $\mathrm{R} \$ 1,11$ bilhão, que juntamente com os recursos destinados ao PAA somaram mais de dois bilhões de reais somente para o ano (MDA, 2016). Com isso "acredita-se que, juntas, as duas iniciativas configurem o maior programa de compras institucionais do mundo que prioriza, deliberadamente, aquisições junto aos agricultores familiares mais vulneráveis (IPC - IG, 2013, p. 7)".

Neste sentido, pode-se inferir que tal política pública à medida que descentraliza e democratiza as compras públicas disponibiliza um importante mercado institucional através da garantia de preços justos. Também, é capaz de reconhecer e criar formas alternativas e cadeias curtas de produção e comercialização de alimentos, na busca pelo respeito aos hábitos alimentares regionais e a vocação agrícola local, valorizar e estimular o desenvolvimento econômico e sustentável das comunidades.

Estudo realizado pelo Centro Internacional de Políticas para o Crescimento Inclusivo - IPCIG (2013) com base em dados fornecidos pelo FNDE aponta que no período de 2010 a 2012, houve uma significa evolução no número de Entidades Executoras (EEx's) que compraram produtos da agricultura familiar para atender as necessidades nutricionais dos alunos, saindo de $48 \%$ em 2010 para 67\% em 2012. Entretanto, as Secretarias Estaduais de Educação, Prefeituras e Escolas Federais das regiões norte e nordeste do país não acompanharam o mesmo ritmo de crescimento. 0 desempenho do gasto médio percentual destas instituições no triênio circundou em torno de $22 \%$, $27 \%$ e $29 \%$, respectivamente, de modo que se possa claramente aferir os intentos de cumprirem o dispositivo legal dos trinta por cento embora crescentes ainda são insuficientes e/ou disformes, uma vez que as EEx's da região sul desde 2011 já passaram a média de 36\%. Destaca-se também que no último biênio pesquisado, $45 \%$ das EEx's cumpriram no país o dispositivo dos trinta por cento das compras destinados a agricultura familiar.

Dentre as principais diretrizes executivas do PNAE para o processo de aquisição de alimentos, estabelecidas pelo arcabouço jurídico da Lei 11.947/2009 e reforçada com a Resolução $n^{\circ}$ 26/FNDE/2013, destacam-se a preferência por alimentos orgânicos ou agroecológicos, oriundos dos mesmos municípios onde se localizam as escolas, com priorização da produção de assentamentos de reforma agrária, comunidades tradicionais indígenas e comunidades quilombolas, e de empreendimentos econômico-solidários formados pela organização dos agricultores familiares. Tais instrumentos também define o processo composto de dez etapas para aquisição, conforme exemplificado na figura 1. 


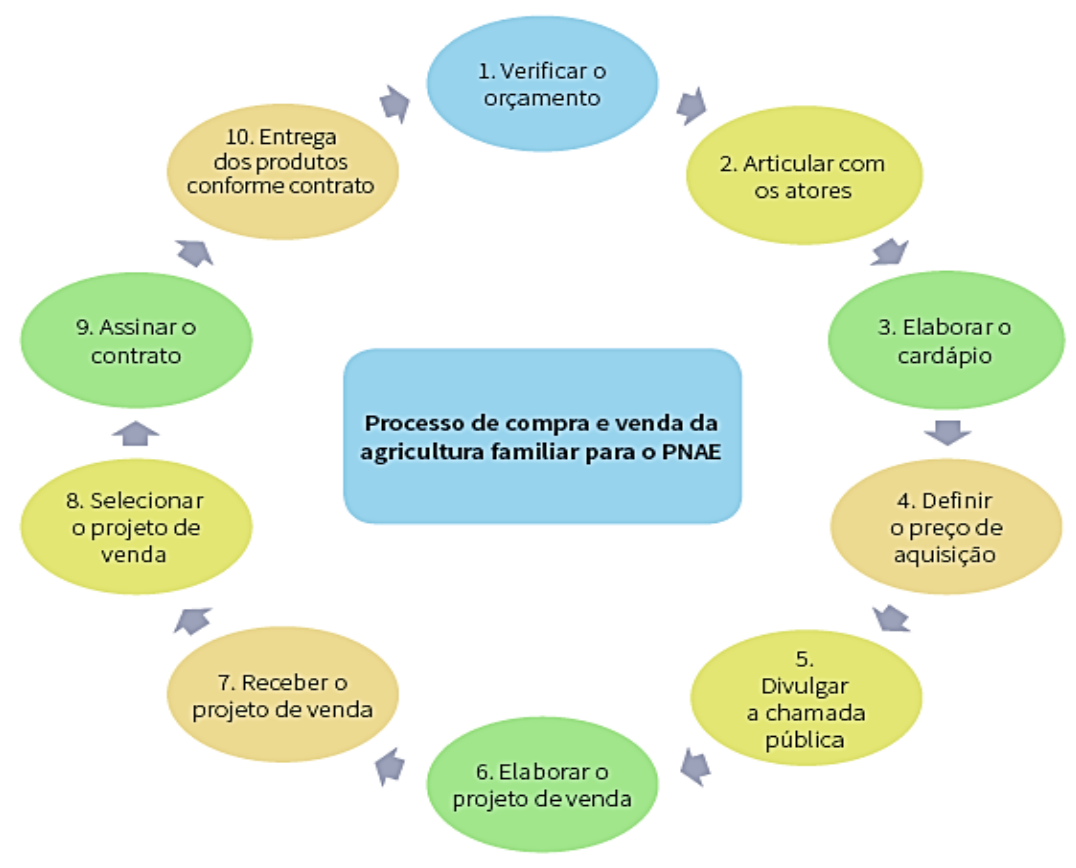

Figura 1 - Processo de Aquisição do PNAE para a agricultura familiar.

Fonte: Brasil, 2014.

O arcabouço do PNAE, e de igual sentido o PAA, é concebido acima de duas correntes desenvolvimentistas: uma localista baseada em estratégias de organização socioterritorial bottomup, outra, a adoção de um enfoque amparado em iniciativas públicas, confirmando o papel do Estado como agente promotor e propulsor do desenvolvimento local, como por exemplo, a criação destes mercados institucionais. Ambos programas "fazem parte integral da estratégia de segurança alimentar e nutricional do Brasil e se cruzam com outras políticas sociais, como as de educação e saúde, bem como a objetivos mais amplos de redução da pobreza e desigualdade" (IPC -IG, 2013, p. 8).

A articulação, transversalidade e interação dessas políticas setoriais, das quais fazem parte também o PRONAF, de políticas redistributivas como o Programa Bolsa Família (PBF) e políticas territoriais, a partir do Programa de Desenvolvimento Sustentável de Territórios Rurais (PRONAT) e o Programa Territórios da Cidadania (PTC), apesar de não serem programas específicos para a agricultura familiar, fundam os alicerces para que o ambiente rural deixe de ser pensado como espaço meramente produtivo e passe a ser compreendido como base no desenvolvimento local pleno, ressaltando as especificidades da determinada localidade desde nuances múltiplas. $O$ resgate desta dimensão "repõe a questão do lugar como posição central", fazendo com que para a análise desta "nova realidade do lugar, não basta um tratamento localista, já que o mundo se encontra em toda a parte (SANTOS, 1996, p. 315).

Do ponto de vista da perspectiva socioterritorial como diretriz para as políticas públicas rurais, o enfoque no perfil econômico e ambiental, na identidade cultural, na coesão social e nos movimentos sociais, empondera os agentes sociais e potencializa o protagonismo local e a construção de uma governança do processo de desenvolvimento em curso. Tal processo corrobora 
para a consolidação de "novos" espaços rurais, desta vez como fruto de relações trabalho/moradia, moradia/mercado de produtos e de serviços, moradia \serviços públicos estatais e questionamento da dicotomia rural versus urbano e do contorno das novas "ruralidades".

\section{METODOLOGIA}

Tal investigação de caráter descritivo buscou-se amparar em técnicas de pesquisa que promovessem o confronto de dados, de indícios e evidências de informações coletadas, somando a estas camadas de interpretações o conhecimento teórico acumulado acerca da temática (Ludke e André, 1986). Assim, adotou-se a combinação de instrumentos de abordagem qualitativa e quantitativa.

Numa perspectiva qualitativa, o trabalho logrou fazer um levantamento documental e bibliográfico que envolvesse diversas temáticas tangentes a agricultura familiar em variados recortes, e, compreender e discutir os impactos e efeitos da execução do PNAE no estado à luz de seu arcabouço teórico-conceitual.

De modo que se realizou a construção de um banco de dados categorizado, composto de 35 variáveis a partir de dados secundários, fornecidos pela Secretaria de Estado da Educação e da Cultura (SEEC), Instituto Brasileiro de Geografia e Estatística (IBGE), Ministério da Educação (MEC) e Ministério do Desenvolvimento Agrário (MDA), foi fundamental para a realização de análises quantitativas e espaciais. Para tanto, a tabulação e tratamento destes dados procedeu-se com base no método de Análise Exploratória de Dados (AED), que segundo Triola (2005) e Field (2009), consiste no processo de uso de instrumentos estatísticos, assim como tabelas, figuras e medidas de centro (média, moda e mediana) para analisar e descrever um determinado conjunto de dados.

A utilização destas ferramentas de pesquisa visou, portanto, analisar criticamente, debater e discutir, comparar e contrastar os resultados obtidos da aquisição de gêneros alimentícios da agricultura familiar pelas escolas sob gestão estadual (EE's) na operacionalização do PNAE durante o período de 2011 a 2013.

\section{O PROGRAMA NACIONAL DE ALIMENTAÇÃO ESCOLAR - PNAE: o cenário do Rio Grande do Norte (2011- 2013)}

O Estado do Rio Grande do Norte possui uma área total de $52.811 .126 \mathrm{~km}^{2}$ e uma população de 3.168.027 habitantes, dos quais das 22,19\% viviam na zona rural (IBGE, 2010). De acordo com o Censo Agropecuário 2006, a agricultura familiar nos 167 municípios que formam seu território está organizada em torno dos 71.210 estabelecimentos agropecuários rurais que representam $86 \%$ dos estabelecimentos agropecuários totais e somam juntos 1.046.131 hectares (33\% das áreas de produção agropecuária), agregando ao valor bruto da produção $R \$ 421$ milhões (38\% do VAB agropecuário ao PIB).

Destaca-se também o relevante número de DAP's no Estado, considerando a função que este dispositivo possui para o acesso as inúmeras políticas públicas, em particular as destinadas ao segmento agropecuário familiar que envolve subvenções econômicas transferidas pelo governo 
federal, a exemplo do PRONAF, PAA e PNAE: até 2014 já tinham sido emitidas 340.059, das quais 133.333 se encontravam ativas (Brasil, 2014), número este quase o dobro do total de agricultores familiares, se compararmos com os dados do Censo Agropecuário 2006.

Segundo Apolinário et al (2009), as variadas atividades agrícolas e suas respectivas cadeias produtivas conformam nove dos 30 Arranjos Produtivos Locais (APLs) existentes nos municípios, tais como a apicultura, mandioca, ovinocaprinocultura, laticínios, polpas/sucos de frutas/água de coco, avicultura, bovinocultura, cajucultura, piscicultura e pesca. O mapeamento e identificação espacial desta diversidade permitem que observemos o potencial que o conjunto de atores econômicos, políticos e sociais que atuam em torno destas cadeias produtivas possuem para o desenvolvimento local e regional. Entretanto, a análise de uma determinada política pública não envolve apenas o cenário e o contexto do segmento ao qual está inserida, cabe também a compreensão e o exame de toda a engenharia institucional e arquitetura organizacional dos aspectos constitutivos que se acercam (SUREL, 2014)

O Programa Nacional de Alimentação Escolar no Rio Grande do Norte funciona de maneira que no âmbito das escolas públicas sob jurisdição do governo do Estado, a coordenação se dê por intermédio da Secretaria de Estado da Educação e da Cultura - SEEC, através da Subcoordenadoria de Assistência ao Educando (SUASE), na qual esta responde pela orientação e supervisão da aquisição gêneros alimentícios destinados à alimentação escolar e pela administração e coordenação de recursos humanos (merendeiras e nutricionistas) e materiais (equipamentos e utensílios) do programa.

Uma vez que o modelo de compras e gestão dos recursos da merenda escolar adotado pelo Estado é descentralizado, cabe as Unidades Executoras das escolas (UEx) receberem os recursos repassados pelo FNDE a SEEC, baseado no número de alunos por escolas, e realizarem a aquisição de alimentos para a merenda escolar, observando o cumprimento do artigo 14 da Lei 11.947/2009 que exige a destinação de $30 \%$ dos recursos financeiros para a compra da produção agrícola familiar e o procedimento licitatório (Registro de preço) para a aquisição dos demais gêneros alimentícios.

O monitoramento do cumprimento destes requisitos legais e da execução do PNAE no RN é realizado pelas Diretorias de Alimentação Escolar (DRAEs). Estes organismos técnicoadministrativos de execução programática consistem em importantes componentes de ligação entre a SUASE e as escolas e respondem pelo levantamento sistemático de dados e informações acerca do programa. O decreto estadual n.o 15.543, de 18 de julho de 2001 define em oito o número de DRAES, cada uma com número circunstanciado de municípios e sediadas em cidades polos de referência: 1a DRAE - Natal (14 Municípios), 2ª DRAE - Nova Cruz (21 Municípios), 3a DRAE - Santa Cruz (15 Municípios), 4a DRAE - João Câmara (22 Municípios), 5a DRAE - Caicó (25 Municípios), 6a DRAE - Mossoró (23 Municípios), 7ạ DRAE - Umarizal (17 Municípios), 8a DRAE Pau dos Ferros (20 Municípios).

A partir de dados levantados junto a SUASE/SEEC e o FNDE, pôde-se observar que no RN desde 2010 (quando a Lei 11.947/2009 passa a ser efetivada) até o exercício de 2012, o percentual dos recursos da alimentação escolar aplicados na aquisição de gêneros da agricultura familiar tem se elevado gradualmente, superando em 2012 a média nacional de $29 \%$ e a regional de $23 \%$. A Figura 2 ilustra esta realidade, na qual os dados nos mostram que entre o período abordado o RN passou de um percentual médio de 10\% em 2010 a 32\% em 2012. 
Observa-se também que para estes anos o país não logrou atingir o percentual mínimo estabelecido, muito embora esteja no limiar deste acontecimento e com uma trajetória de crescimento nos resultados, saindo dos 22\% em 2010 e passando a 29\% em 2012.
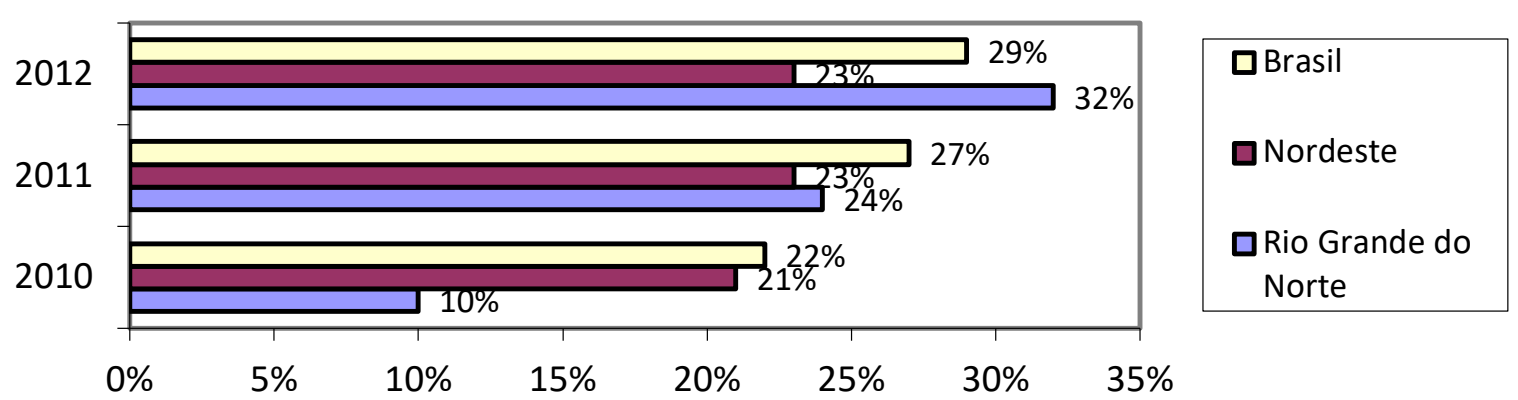

Figura 2 - Percentual médio dos recursos do PNAE aplicados na aquisição de gêneros da agricultura familiar pelo RN, Nordeste e Brasil, entre 2010 e 2012.

Fonte: Elaboração própria, baseado em dados do FNDE e SUASE/SEEC, 2016.

O plano regional pode ser um dos percalços para a lenta ascensão destes valores, considerando que os resultados do Norte e do Nordeste ainda apresentam debilidades. Ao analisar as justificativas para o não atendimento aos requisitos legais dos $30 \%$ dos recursos nas compras da agricultura familiar no Brasil e, sobretudo nestas regiões, Saraiva et al. (2013) descreve que a impossibilidade de emissão de nota fiscal, condições higiênico-sanitárias inadequadas e a inviabilidade de fornecimento constante e regular de gêneros alimentares agrícolas são as principais problemáticas elencadas para o descumprimento do dispositivo legal.

Conforme Cunha et al.(2014) e relatos das nutricionistas e gestores do programa, no RN, agregado a estes fatores estão as dificuldades burocráticas e emissão de DAPs, a falta de produtos com o autorização sanitária e ausência de abatedouros com registros, a baixa variedade de produtos, a pouca experiência dos agricultores familiares em processos de chamada pública e o diálogo com outros atores locais e instituições, falta de profissionalização das merendeiras e os custos relacionados ao transporte dos alimentos.

Embora a descentralização dos recursos em andamento desde 1994 e a regionalização da gestão da merenda pós 2001 tenham sido marcos que garantiram avanços importantes para a política no estado, considerando que "a escolarização pode facilitar a logística na distribuição de produtos perecíveis, como verduras, frutas e legumes, e poderia trazer como vantagem o fato de que os produtos utilizados estejam mais frescos, já que a cadeia de distribuição seria mais curta (BELIK; CHAIM, 2009, p. 600)", ao examinar os dados das escolas públicas estaduais reunidos por DRAEs nos deparamos com cenários bastante contrastantes, conforme nos mostra a tabela 1.

Com base na tabela infere-se que no ano de 2013 houve uma ruptura da trajetória ascendente de crescimento no percentual de recursos aplicados na agricultura familiar norte-riograndense iniciada em 2010, puxada pelo mau desempenho das DRAES 2, 4, 5, 6 e 7. Ao mesmo tempo, a crise mundial e a pressão inflacionária na produção e consumo de alimentos, através do aumento dos custos de produção (energia, combustíveis, transportes), e problemas no abastecimento interno pelos reflexos da maior e "mais prolongada seca dos últimos 50 anos" 
(CNM, 2014, p. 160), com a morte de rebanhos e a quebra das safras, provocaram interferências na produtividade agrícola local e regional.

Tabela 1 - Percentual de aquisição de gêneros alimentícios da agricultura familiar por DRAEs no Rio Grande do Norte, de 2011 a 2013.

\begin{tabular}{lccc}
\hline DIRETORIA REGIONAL (DRAE) & $\mathbf{2 0 1 1}$ & $\mathbf{2 0 1 2}$ & $\mathbf{2 0 1 3}$ \\
\hline $1^{\circ}$ DRAE - Sede Natal & $30,0 \%$ & $29,7 \%$ & $32,2 \%$ \\
\hline $2^{\text {o }}$ DRAE - Sede Nova Cruz & $5,6 \%$ & $22,8 \%$ & $24,5 \%$ \\
\hline $3^{\circ}$ DRAE - Sede Santa Cruz & $26,9 \%$ & $36,6 \%$ & $36,0 \%$ \\
\hline $4^{\circ}$ DRAE - Sede João Câmara & $17,1 \%$ & $51,0 \%$ & $26,7 \%$ \\
\hline $5^{\circ}$ DRAE - Sede Caicó & $4,4 \%$ & $19,0 \%$ & $13,1 \%$ \\
$6^{\circ}$ DRAE - Sede Mossoró & $30,2 \%$ & $29,5 \%$ & $10,6 \%$ \\
$7^{\circ}$ DRAE - Sede Umarizal & $12,8 \%$ & $30,0 \%$ & $25,9 \%$ \\
\hline $8^{\circ}$ DRAE - Sede Pau dos Ferros & $25,4 \%$ & $43,3 \%$ & $36,7 \%$ \\
\hline RIO GRANDE DO NORTE & $\mathbf{2 4 , 2 \%}$ & $\mathbf{3 2 , 2 \%}$ & $\mathbf{2 2 , 3 \%}$ \\
\hline
\end{tabular}

Fonte: Elaboração própria, baseado em dados da SUASE/SEEC, 2016.

No entanto, as DRAEs com sede em Natal, Santa Cruz e Pau dos Ferros conseguem cumprir os $30 \%$ exigidos e, juntas, aportaram cerca de $R \$ 3.524 .691 .45$ ou $63,3 \%$ de todo o valor gasto na aquisição junto à agricultura familiar. No caso da primeira, se comparado aos valores relativos a 2012 , amplia timidamente o percentual, passando de $29,7 \%$ para $32,2 \%$, em contraponto com a terceira que teve leve redução e oitava DRAE que após quase dobrar os resultados percentuais sofreu queda em 6,6\% em comparação ao valor do ano anterior.

Destaca-se no desempenho traçado no exercício financeiro de 2012 metade das diretorias regionais alcançou o percentual parametrizado (DRAEs 3, 4, 7 e 8) que consistem o universo de 186 escolas ( $27,6 \%$ do total) e atendem cerca de 58.529 alunos - ou seja, $1 / 5$ dos estudantes de escolas públicas estaduais - sendo responsáveis por contribuir na agricultura familiar com R\$ 1.161.957.08, isto é, $13,6 \%$ do valor total repassado pelo FNDE à SEEC para ser gasto na compra da alimentação escolar. Alinhado as metas propostas pela SUASE, que é chegar ao percentual de $70 \%$ até 2014, a regional de João Câmara foi a primeira a ultrapassar os limites de $51 \%$ no gasto dos recursos com a produção agrícola local, mesmo que conseguintemente não tenha sustentado este valor e diminua para $26,7 \%$.

Já as outras duas - DRAEs 1 e 6 - tangenciaram a aplicação da exigência o que para o contexto que representam é bastante significativo, uma vez que juntas possuem mais de $1 / 2$ das escolas (352) e 177.728 alunos (62,3\% do total para o ano) e seus desempenhos por estarem localizadas em regiões dinâmicas da economia sevem de paradigma para os demais, também, por representarem em média uma demanda estruturada de 3,7 milhões/ano. Em 2012, os recursos transferidos pelo FNDE ao Estado reduziram em 1/3, sentida duramente pela também chamada 
DRAE Metropolitana $\left(1^{\circ}\right)$ que passou por fortes reduções no volume de recursos, caindo de $\mathrm{R} \$$ 10.037.195.60 para $\mathrm{R} \$ 1$ 1.072.159.80, devido a problemática das escolas com a prestação de contas dos anos anteriores.

As regionais de Nova Cruz e Caicó, mesmo não situando acerca do mínimo estabelecido, apresentaram em 2012 ensaiaram uma melhora importante nos seus índices - em que pese o cenário de diminuição de $48.8 \%$ nos recursos, transposto de $\mathrm{R} \$ 3.452 .805 .60$ para $\mathrm{R} \$ 1$ 1.683.610.99 em meio ao decréscimo de 1609 alunos e o fechamento de duas escolas - passando a atingir percentuais com dígitos, 22,8 e 19\% respectivamente, a partir da aplicação de $\mathrm{R} \$ 373.494 .22$ na agricultura familiar nos municípios em que fazem parte de suas jurisdições.

Em suma, o que se pode perceber é que ao longo do triênio 2011-2013 o panorama das DRAES nos sugere perspectivas distintas e conflitivas que embasam a existência de três perfis: o primeiro de resultados estáveis com pequenas alterações nos percentuais, vezes para baixo e outras para cima; o seguinte, com diretorias que traçam oscilações drásticas no percentual, saindo de números tímidos a valores expressivos e assim por diante; e por último, regionais com baixo desempenho no atendimento ao percentual preconizado, em que pese se localizarem em territórios com dinamismo econômico. A Figura 3 nos auxilia na compreensão desses fenômenos tão distintos.

No tocante a vocação e tradição agrícola dos municípios e o desenvolvimento da economia local (aspectos basilares do PNAE), o exame do desempenho das DRAEs no RN nos revela que não há necessariamente uma correlação do bom desempenho no atendimento dos percentuais e na promoção da agricultura familiar. Como exemplo, a $5^{\circ}$ DRAE pode ser usada como parâmetro, pois embora situe como uma das regiões agrícolas mais dinâmicas do estado e o VAB agropecuário seja representativo para a composição do PIB local em 2011 (8.4\% das riquezas totais produzidas pelos municípios advém deste segmento) esta possui baixo desempenho na execução do PNAE. Apesar de ter o potencial de investir mais de $\mathrm{R} \$ 360 \mathrm{mil} / \mathrm{ano}$ com os repasses do FNDE, os municípios da regional não souberam aproveitar tal demanda e conseguiram captar uma média anual menor que $1 / 3$ deste valor.

De maneira similar, a DRAE com sede em Nova Cruz também não consegue utilizar as potencialidades e variedade agrícola local e canalizar os esforços para estruturar a demanda institucional nos municípios que a formam, ainda que tenha obtido avanços nos resultados e nos mecanismos de gestão. Cunha et al. (2014) evidencia em seu trabalho que até 2011 apenas 33\% das 57 escolas compravam alimentos diretamente da agricultura familiar, o que apontava a pequena adesão dos gestores escolares no que diz respeito ao cumprimento da legislação, demonstrando assim, a necessidade da SUASE e das DRAEs intensificarem nas escolas aquisição dos gêneros oriundo da agricultura familiar.

A Figura 3 nos mostra também as DRAEs 3, 4 e 7, que apresentam uma variação do VAB agropecuário entre $4.2 \%$ e $6.6 \%$ do PIB para 2011, desenha cada uma sua própria trajetória, a exemplo da DRAE 4. Nesta última de 4 dos seus 22 municípios possuírem mais de $20 \%$ de seus PIBs voltados para o setor agrícola (Touros, Taipu, São Miguel do Gostoso e Caiçara do Norte), com exceção do alto desempenho conquistado em 2012, não consegue estabelecer um caminho sólido, ascendente e linear na incorporação dos produtos agrícolas familiares na merenda de suas 51 escolas e 13.899 alunos, assim como a DRAE 7, que logo após lograr atender a legislação, sofre uma diminuição no percentual aplicado. 


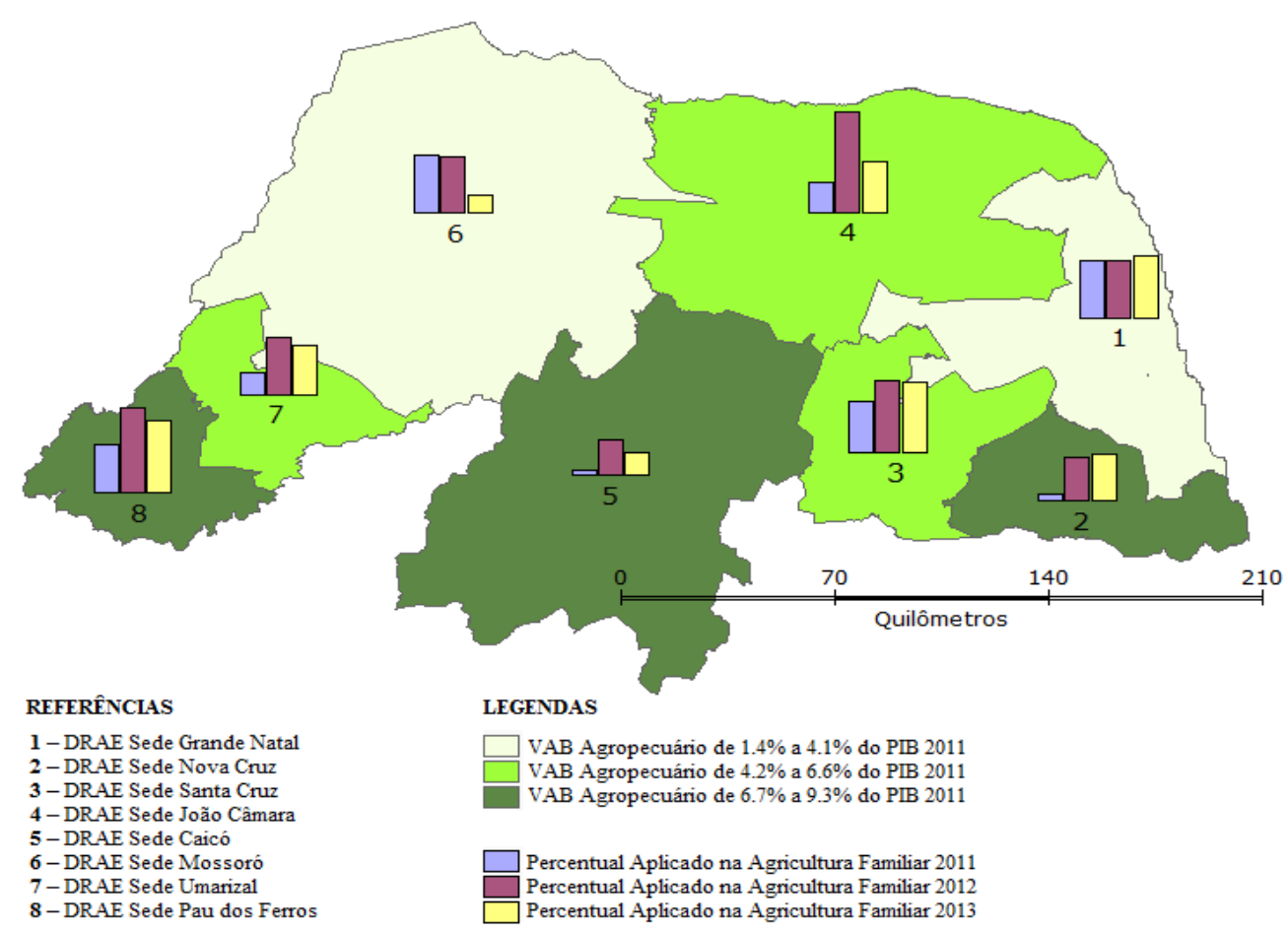

Figura 3 - Percentual aplicado na Agricultura Familiar e do Valor Agregado Bruto (VAB) Agropecuário por Diretoria Regional de Alimentação Escolar (DRAEs).

Fonte: Elaboração própria, baseado em dados da SUASE/SEEC e IBGE, 2016.

É importante destacar também que considerada a diversidade social destes territórios, o PNAE aloca valores diferenciados para atender as diversidades étnicas e as necessidades nutricionais por faixa etária e vulnerabilidade social, com destaque a priorização dos assentamentos de reforma agrária, as comunidades tradicionais indígenas e remanescentes quilombolas. A Figura 4, juntamente com os dados da Tabela 1, revelam que grande parte das escolas localizadas nos municípios com comunidades indígenas e/ou quilombolas e as DRAES não têm se articulado para potencializar seus resultados diante destas oportunidades.

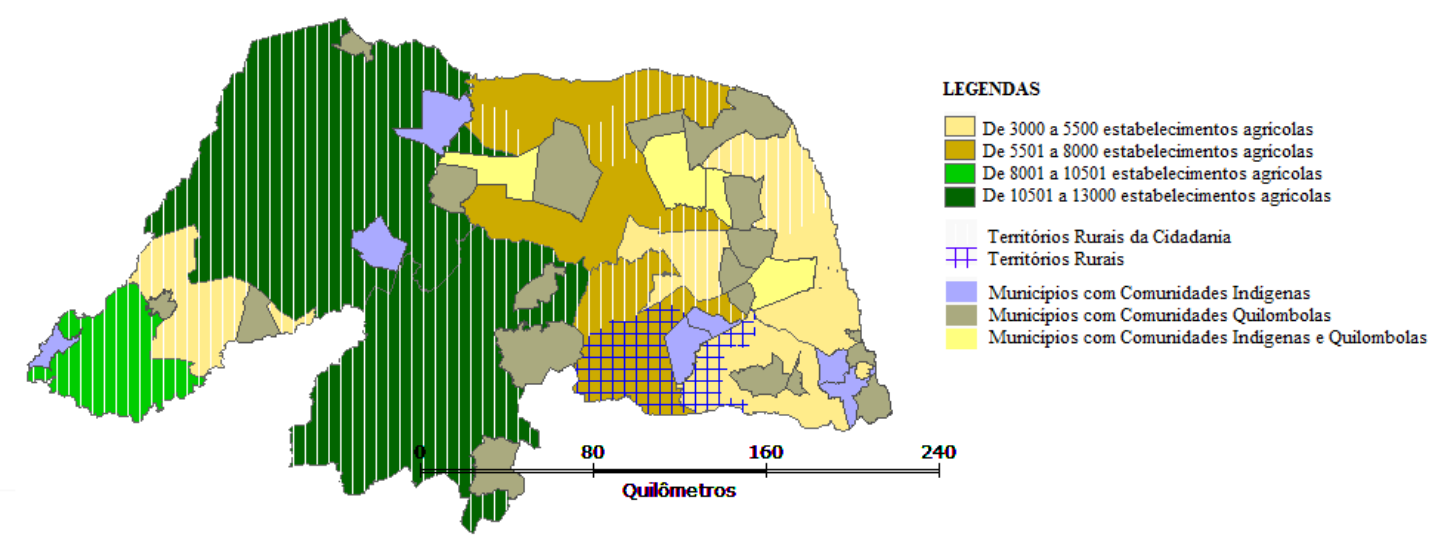

Figura 4 - Municípios com Comunidades Indígenas e/ou Quilombolas e Número de estabelecimentos agrícolas por Diretoria Regional de Alimentação Escolar (DRAEs) e Territórios Rurais e da Cidadania 
Fonte: Elaboração própria, baseado em dados do Ministério do Desenvolvimento Agrário e SUASE/SEEC, 2016

Apesar de 130 município do Estado pertencerem aos territórios rural e rural da cidadania (mais de $80 \%$ do total), que consistem em importantes iniciativas do Governo Federal para maximizar as políticas públicas em uma lógica de planejamento territorial integrado, e todas as DRAES possuírem porções de terras integrantes - as diretorias 3,5,6,7 e 8 possuem todo seu território imerso nestes - não constata-se uma grande influência e articulação destas iniciativas no desempenho obtido na atenção do percentual estabelecido. Pondera-se que, aliado a ao fato relatado anteriormente, está a recomendação do FNDE de que as compras de gêneros alimentícios sejam feitas, sempre que possível, no mesmo município que se localiza a escola, e, caso não logrem adquirir a totalidade dos produtos da agricultura familiar no próprio município, deverão priorizar projetos oriundos de outros municípios que compõem o território rural do qual fazem parte.

Além disso, nos 30 municípios que possuem estas comunidades a média percentual da destinação de recursos a agricultura familiar é de 24,6\% para o triênio 2011-2013, em que pese que tem um percentual médio da VAB agropecuária em torno dos $9 \%$ e $2 / 3$ deles estão situados em nenhum território Dos municípios que integram territórios rurais, nenhum atingiu média igual ou superior aos 30\%, enquanto dois municípios do território rural da cidadania Açu-Mossoró (Carnaubais e Grossos) sob jurisdição da $6^{\circ}$ DRAE, apresentaram resultados satisfatórios. No primeiro, apesar da agropecuária contribuir apenas com 3,3\% do PIB em 2011 e ter apenas uma comunidade indígena, os recursos destinados por suas 2 escolas à compra de gêneros agrícolas atingiu uma média de $33.1 \%$ para os três anos, ou seja, aportaram mais de R\$ 43 mil. Já o segundo, mesmo com somente 118 estabelecimentos da agricultura familiar, $25.1 \%$ de sua população em área rural e com 4 comunidades quilombolas, suas duas escolas públicas estaduais com 988 alunos, tiveram um desempenho médio de $38 \%$, favorecidas pelo fato da agricultura ter uma relevância significativa na composição do Produto Interno Bruto (PIB) - 9.9\%. Em meio a estes, desperta bastante atenção o fato do Afonso Bezerra, que possui uma comunidade indígena e uma quilombola e $46,7 \%$ de sua população vive no campo, não pertencer a nenhum dos territórios rurais e/ou da cidadania e ter um desempenho médio de $33,3 \%$.

Outra análise que se permite fazer é que, assim como a vocação e tradição agrícola de uma região, o alto número de empreendimentos agrícolas e organizações produtivas da agricultura familiar (associações ou cooperativas) não possuem uma correlação direta no desempenho das Diretorias Regionais de Alimentação Escolar (DRAEs) do Rio Grande do Norte. Conforme dados do Mapeamento das Organizações Sociais e de Produtores Familiares do Rio Grande do Norte (Rio Grande do Norte, 2014) expostos na Figura 5, as DRAEs com sede em João Câmara, Caicó e Mossoró são as que mais possuem em seus municípios o maior número de associações ligadas a agricultura familiar, concentrando quase metade deste valor.

Fixe a $5^{\circ}$ DRAE, que muito embora abarque 413 associações e 5 cooperativas, isto é, 16,6\% das organizações sociais do RN, não consegue ter uma performance exitosa na busca pelo atendimento dos dispositivos legais exigidos para alimentação escolar - sua média durante o período de 2011 a 2013 é de $12,2 \%$, o mais baixo de todas as DRAEs. 


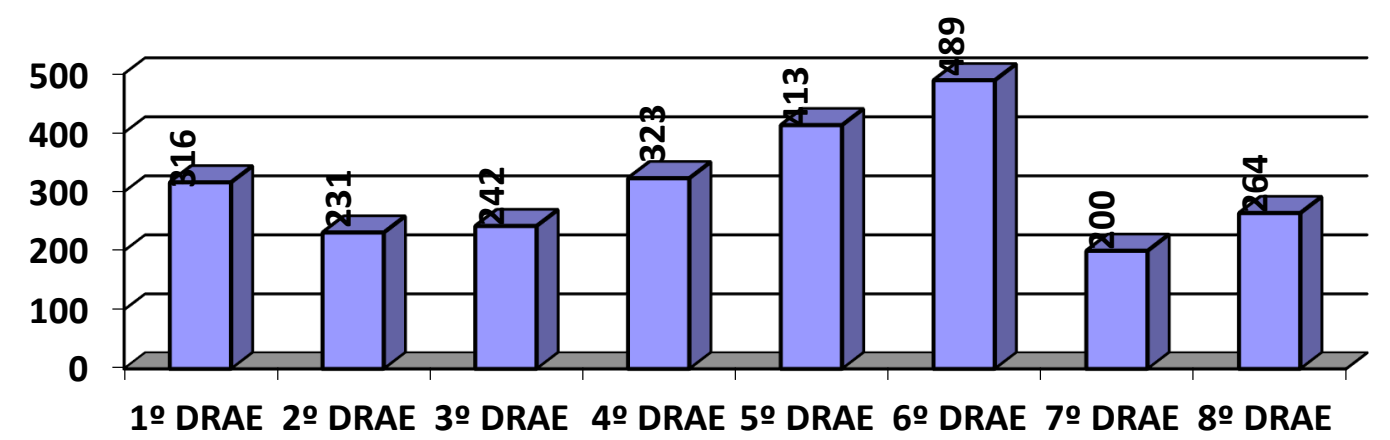

Figura 5 - Número de Associações de Produtores da Agricultura Familiar por Diretoria Regional de Alimentação Escolar (DRAEs)

Fonte: Elaboração própria, baseado em dados do Governo do Rio Grande do Norte, 2016.

Sob a ótica da economia solidária, tais empreendimentos econômico-produtivos constituem elementos importantes para que os agricultores familiares tenham acesso ao mercado institucional e possam participar com DAP jurídica da comercialização de seus produtos, uma vez que os grupos formais têm prioridade sobre os demais. Logo, o acesso e a construção de mercados diferenciados de podem ser potencializados na medida em que os agricultores estiverem organizados. Por meio de associações e cooperações, os agricultores criam melhores oportunidades de trabalho e fortalecem a comunidade de forma solidária, organizando a produção e facilitando o acesso aos mercados consumidores, com inclusão social e desenvolvimento local. Por isso, o PNAE incentiva a organização, priorizando os agricultores familiares organizados em associações e cooperativas (BRASIL, 2014). Além da demanda estruturada governamental, "as cooperativa, claro, aumentam, o acesso de muitos pequenos agricultores ao mercado (IPC-IG, 2013, p. 30)".

Entretanto, das 2.513 organizações sociais e de produtores familiares presentes no RN (2.479 associações e 34 cooperativas) apenas $6 \%$ das participam efetivamente dos conselhos municipais de alimentação escolar (CMAE's) e 14\% e 21\% de fóruns de articulação da sociedade civil da Economia solidária e territórios rurais da cidadania, respectivamente. Além disto, $1 \%$ destas organizações utilizam os recursos do PNAE para financiar seus projetos ao passo que $5 \%$ delas recorrem aos recursos do PAA.

Tais constatações sinaliza a necessidade de reflexão acerca do desenho da política pública em estudo, será que esta necessita de mudanças incrementais adequadas a realidade? Em estudos sobre políticas públicas para agricultura familiar Aquino e Schneider (2011) constaram ao analisar 12 anos de execução do Programa Nacional de Fortalecimento da Agricultura Familiar (Pronaf), que de modo geral, as ações públicas desenvolvidas para agricultura familiar "não é condição suficiente para provocar mudanças profundas no padrão sócio-técnico de produção que vigora no meio rural brasileiro" (Aquino e Schneider, 2011, p. 333).

Assim, para que o conjunto de políticas como Pronaf, PAA, PNAE e entre outros, que resguardam em comum a focalização para a agricultura familiar necessitam de maior integração entre si e também "com outras ações governamentais na área de redistribuição fundiária, educação rural, assistência técnica, melhoria da infraestrutura rural e difusão de tecnologias menos agressivas ao meio ambiente" (Aquino e Schneider, 2011, p. 333). 


\section{CONSIDERAÇÕES FINAIS}

As inferências, informações e estatísticas aqui apresentadas se somam como expressões dos avanços, ganhos e consolidações aos quais permearam a agricultura familiar brasileira nos dois últimos decênios, mas também como material reflexivo acerca dos desafios, tendências e alternativas a serem enfrentados pelos produtores familiares, em particular aos norte-riograndenses.

Embora tenhamos uma sólida institucionalidade construída, começando pela tríade de políticas públicas para e/ou envoltas a agricultura familiar, exemplo das setoriais (PRONAF, PAA) e intersetoriais (caso do PNAE), passando pelas políticas redistributivas (PBF) e políticas territoriais (PRONAT, PTC), a desarticulação das políticas, e bem como também a falta de estruturação dos produtores e instituições locais com os agentes e os territórios, a desintegração entre a comunidade, segmentos governamentais e sociais (setor privado e terceiro setor) ainda é uma realidade que persiste na agricultura familiar. O caso do Programa Nacional de Alimentação Escolar (PNAE) no âmbito das escolas públicas estaduais do Grande do Norte entre os anos de 2011 a 2013 ilustram este cenário.

Nos três anos abordados o programa já aportou mais de $\mathrm{R} \$ 55$ milhões no estado, garantindo assim um mercado institucional de no mínimo 16,5 milhões de reais. Apesar disto, observou-se uma perda de oportunidade ímpar: do total, apenas $\mathrm{R} \$ 13,6$ foi aportado na aquisição de gêneros alimentícios para a merenda escolar para quase 280 mil alunos das 657 escolas estaduais, atingindo assim o valor médio de $26,2 \%$ ao longo do triênio.

Espera-se, portanto, que as mudanças apresentadas pelo FNDE através da Resolução 26/2013 na qual tentam resolverem questões referentes ao aumento do limite anual do valor de compras dos produtores familiares individuais, da incorporação das despesas com frete, embalagens e demais encargos para a distribuição física dos produtos, face aos diversos entraves interpostos a comercialização, ajudem na melhoria dos percentuais não apenas do Rio Grande do Norte mais também em outros Estados do Nordeste e do país. Ademais, os esforços empreendidos pelo Governo do Estado em busca de desenvolver parcerias com as instituições do setor público e privado, assim como organizações sociais diversas, na profissionalização e gestão do programa, podem tornar tal política pública mais efetiva, eficaz e eficiente.

De modo que, existem desafios a serem superados e necessita da efetividade de políticas mais duradouras que saiam do patamar das emergências para efetivação. Deve-se ressaltar a necessidade de discutir de forma integrada as políticas públicas focalizadas na agricultura familiar de modo que tratem dos temas como o acesso a recursos como terra, água, crédito e assessoramento técnico, bem como a dinamização dessas políticas públicas no intuito de atender um número cada vez maior de municípios, associações, cooperativas, grupos formais e informais de famílias de agricultores. Além de realizar estratégias que fortaleçam a participação de todos os atores nas tomadas de decisões, buscando o envolvimento dos gestores municipais nas discussões criando um ambiente propício com os arranjos necessários a implementação e a gestão das políticas de modo a promover um desenvolvimento territorial.

Ressalta-se que a participação dos atores sociais tem fundamental importância no processo de construção e implantação de políticas públicas através da cooperação mútua entre eles. 
Porém, o processo de governança nas políticas públicas é desafiador aos arranjos institucionais em diversos aspectos, por exemplo, quando existem influências externas que chegam ao território, dificultando o processo de construção coletiva dos atores, desrespeitando os costumes e a cultura local. Assim, governança das políticas públicas para agricultura familiar precisa estar regada de informações, ter discernimento dos interesses coletivos e habilidade para lidar com os conflitos existentes entre os diferentes atores sociais, sem perder a essência da construção democrática de gestão, mas com vias a trazer maior efetividade das políticas públicas para agricultura familiar em vigor.

\section{REFERÊNCIAS}

Apolinário, V. (Coord.) (2009). Caracterização, análise e sugestões para adensamento das de apoio a APLs implementadas nos estados - Rio Grande do Norte. Projeto de Pesquisa. In: BNDES/FUNPEC. Análise do Mapeamento e das Políticas para Arranjos Produtivos Locais no Norte, Nordeste e Mato Grosso e dos Impactos dos Grandes Projetos Federais no Nordeste. Natal/RN: BNDES e FUNPEC.

Centro Internacional de Políticas para Crescimento Inclusivo - IPC-IG (2013). Demanda Estruturada e Pequenos Agricultores no Brasil: o Caso do PAA e PNAE 2013. Brasília: PNUD.

Alves, E (2014). Dualidade da agricultura brasileira. Revista de Política Agrícola, Brasília, DF. v. 23, n. 4, p. 3-4, Out./Nov./Dez.

Alves, E.; Marra, R (2009).A persistente migração rural-urbana. Revista de Política Agrícola, Brasília, DF, ano 18, n. 4 , p. 5-17, out./dez.

Alves, E. R. de A.; Souza, G. da S. e; Rocha, D. de P.; Marra, R (2013). Fatos marcantes da agricultura brasileira. In: Alves, E. R. de A.; Souza, G. da S. e; Gomes, E. G. (Ed.). Contribuição da Embrapa para desenvolvimento da agricultura no Brasil. Brasília, DF: Embrapa.

Aquino, J. R. ; Schneider, S. (2011) . 12 Anos da política de crédito do PRONAF no Brasil (1996-2008): uma reflexão crítica. Revista de Extensão e Estudos Rurais, v. 1, p. 309-347.

Aquino, J. R.; Radomsky, G. F.W; Spohr, G; Schneider, S (2011). Dimensão e localização do público potencial do PRONAF "B" no Brasil: uma análise a partir do Censo Agropecuário 2006. In: Anais do Congresso Brasileiro de Economia, Administração e Sociologia Rural, 49, 2011, Belo Horizonte/MG: SOBER.

Araújo, T. B (2000). Ensaios sobre o desenvolvimento brasileiro. Heranças e urgências. Rio de Janeiro: Fase.

Belik, W.; Chaim, N. A (2009). O programa nacional de alimentação escolar e a gestão municipal: eficiência administrativa, controle social e desenvolvimento local. Revista de Nutrição, v. 22, n. 5, p. 595-607, set./out.

Brasil (2014). Aquisição de produtos da agricultura familiar para a alimentação escolar. Brasília: FNDE. 
Brasil (1996). Decreto Presidencial 1.946, de 28 de Junho de 1996. Cria o Programa Nacional de Fortalecimento da Agricultura Familiar - PRONAF, e dá outras providências.

Brasil (2016). Folders Pnae. Recuperado em: 10 jan. 2016 de http://www.fnde.gov.br/programas/alimentacao-escolar/alimentacao-escolar-material-dedivulgacao/alimentacao-manuais/item/5842-folder-pnae .

Brasil (2016). Manual do Agente emissor de Declaração de Aptidão ao PRONAF. Brasília: Ministério do Desenvolvimento Agrário, 2014. Recuperado em 15 fev. 2016 de http://dap.mda.gov.br/dapweb/ManualDAP/MANUAL\%20DO\%20AGENTE\%20EMISSOR.pdf

Brasil (2015). Plano Safra da Agricultura Familiar 2015/2016. Brasília: Ministério do Desenvolvimento Agrário.

Companhia Nacional de Abastecimento - CONAB (2015). O Programa de Aquisição de Alimentos como Modelo de Política Pública a ser Compartilhada com outros Países. Brasília: Ministério do Desenvolvimento Agrário. Recuperado em 2 fev. 2016 de http://www.conab.gov.br/OlalaCMS/uploads/arquivos/16_01_27_15_00_43_paa_modelo.p df.

Confederação Nacional ee Municípios - CNM (2014). Análise sobre a seca no Nordeste. In: CNM (volume 6, 2014). Estudos Técnicos CNM. Brasília: CNM, pp. 160-176.

Cunha, A.; Assis Júnior, I.; Dias, T. F. (2014). Promoção do desenvolvimento rural via políticas públicas: o caso da inserção da agricultura familiar no Programa de Alimentação Escolar no Rio Grande do Norte de 2011 - 2012. Revista Tekhne e Logos, Botucatu/SP, v. 5, n.2, dezembro.

Dagnino, E (2004). Construção democrática, neoliberalismo e participação: os dilemas da confluência perversa. Política \& Sociedade: Revista de Sociologia Política, Florianópolis/SC, vol. 1, n. 5.

Fernandes. B. M (2006). Questão agrária. In: Sader, E. ; Jinkings, I. - Coords. (2006). Enciclopédia Contemporânea da América Latina e do Caribe. São Paulo: Boitempo editorial.

Grisa, C.; Schimitt, S.; Mattei, F. L (2009). O Programa de Aquisição de Alimentos (PAA) em perspectiva: apontamentos e questões para o debate. Rio de Janeiro: Observatório de Políticas Públicas para Agricultura (OPPA): UFRJ.

Grisa, C.; Schneider, S. Brasil: dos décadas de políticas públicas para la agricultura familiar. In: Sabourin, E. ; Samper, M.; Sotomayor, O. (Coord.). (2014). Políticas públicas y agriculturas familiares en América Latina y el Caribe: Balance, desafíos y perspectivas. Santiago: CEPAL.

Lopéz, M. G. A (2004). Es posible la integración de organizaciones autónomas de pequeños productores agroalimentarios en América Latina? In: Lopéz, M. G. A; Valencia, A. S. -Coords. (2004). Reestructuración y desarrollo en América Latina. México: Siglo XXI, 2004.

Lüdke, M.; André, Marli E.D.A. (1986). Pesquisa em educação: abordagens qualitativas. São Paulo: EPU. 
Martins, C. E (2006). Consenso de Washington. In: Sader, E. ; Jinkings, I. - Coords. (2006). Enciclopédia Contemporânea da América Latina e do Caribe. São Paulo: Boitempo editorial.

Pinto, H. S. A Segurança Alimentar e Nutricional no Brasil (Parte 1): A Modernização do Estado e os Avanços na Superação da Fome. Brasília: Núcleo de Estudos e Pesquisas/CONLEG/Senado, Agosto/2014 (Texto para Discussão no 150). Recuperado em 9 abril. 2015 de www.senado.leg.br/estudos.

Pinto, H. S. (2014). A Segurança Alimentar e Nutricional no Brasil (Parte 2): Desafios Atuais. Brasília: Núcleo de Estudos e Pesquisas/CONLEG/Senado, agosto/2014 (Texto para Discussão no 152). Recuperado em 9 abril. 2015 de www.senado.leg.br/estudos.

Putnam, R. D (1996). Comunidade e democracia: a experiência da Itália moderna. Rio de Janeiro: Fundação Getúlio Vargas.

Rio Grande Do Norte (2014). Mapeamento das Organizações Sociais e de Produtores Familiares do Rio Grande do Norte. Natal: RN SUSTENTÁVEL.

Triola, M. F (2005). Introdução à Estatística. 9 ed. Rio de Janeiro: LTC.

Turpin, M. E (2009). A alimentação escolar como fator de desenvolvimento local por meio do apoio aos agricultores familiares. Segurança Alimentar e Nutricional. Campinas, 12(2), pp. 20-42.

Sabourin, E.; Samper, M.; Sotomayor, O. (Coord.). (2014). Políticas públicas y agriculturas familiares en América Latina y el Caribe: Balance, desafíos y perspectivas. Santiago: CEPAL, 2014. Recuperado em 2 fev. 2016 de http://repositorio.cepal.org/bitstream/handle/11362

/37193/S1420694es.pdf;jsessionid=02F2BD9AB9DF2F9335BEE629764F9ABF?sequence=1

Santos, M. (1996) O lugar e o cotidiano. In: Santos, M. A natureza do espaço, 2. Edição. São Paulo: Editora Hucitec.

Saraiva E.B; Silva, A. P.; Souza, A. A.; Cerqueira, G. F.; Chagas, C. M.; Toral, N. (2013). Panorama da compra de alimentos da agricultura familiar para o Programa Nacional de Alimentação Escolar. Revista Ciência \& Saúde Coletiva, vol.18, n.4, pp.927-935. Rio de janeiro.

Schimitt, C.J; Tygel, D. (2009). Agroecologia e Economia solidária: trajetórias, confluências e desafios. In: Petersen, P. (org.). Agricultura familiar camponesa na construção do futuro. Rio de Janeiro: AS-PTA.

Silva, W. H.; Silva, M. A.; Brandão, V. S.; Silva, E. A.; Teixeira, P. S. D. (2014). Agricultura Familiar e Mercados Institucionais: uma análise acerca da operacionalização do Programa Nacional de Alimentação Escolar no município de Unaí, MG. In: Anais do Congresso Brasileiro de Economia, Administração e Sociologia Rural, 52, Goiânia/GO.

Sparovek, G.; Ludwig, A. E. P.; Maule, R. F. (2007). Estudo comparativo das diferentes modalidades do PAA - Região Nordeste. Caderno de Estudos e Desenvolvimento Social em debate. n. 5. Brasília: MDS. 
Surel, Y. (2014). L'État et les politiques publiques. In: Jourcin, E. (Coord.). (2014). Les enjeux du développement en Amérique latine. Dynamiques socioéconomiques et politiques publiques. 10 ed. Paris: Institut des Amériques. 